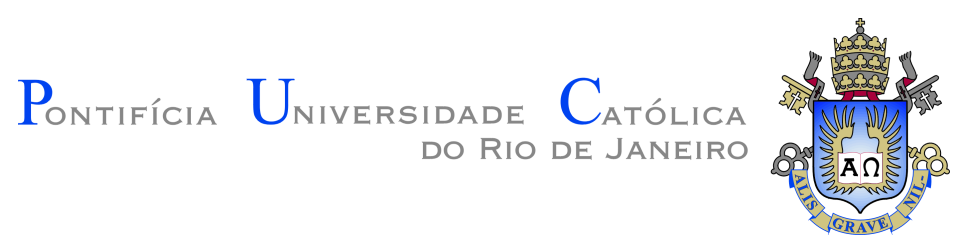

Tomás Frederico Maciel Gutierrez

\title{
Can Asset Allocation Limits Determine Portfolio Risk-Return Profiles in DC Pension Schemes?
}

Dissertação de Mestrado

Thesis presented to the Programa de Pós-graduação em Engenharia de Produção da PUC-Rio in partial fulfillment of the requirements for the degree of Mestre em Engenharia de Produção

Advisor : $\quad$ Prof. Davi Michel Valladão Co-advisor: Prof. Bernardo Kulnig Pagnoncelli 


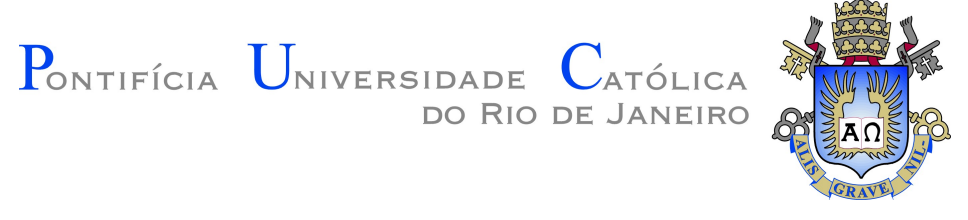

Tomás Frederico Maciel Gutierrez

\section{Can Asset Allocation Limits Determine Portfolio Risk-Return Profiles in DC Pension Schemes?}

Thesis presented to the Programa de Pós-graduação em Engenharia de Produção da PUC-Rio in partial fulfillment of the requirements for the degree of Mestre em Engenharia de Produção. Approved by the Examination Committee.

Prof. Davi Michel Valladão

Advisor

Departamento de Engenharia Industrial - PUC-Rio

Prof. Bernardo Kulnig Pagnoncelli

Co-advisor

Universidad Adolfo Ibáñez/Chile

Prof. Bruno Fânzeres dos Santos

Departamento de Engenharia Industrial - PUC-Rio

Prof. Álvaro de Lima Veiga Filho

Departamento de Engenharia Elétrica - PUC-Rio 
All rights reserved.

\section{Tomás Frederico Maciel Gutierrez}

Majored in Industrial Engineering by the Pontifical Catholic University of Rio de Janeiro - PUC-Rio

Bibliographic data

Gutierrez, Tomás Frederico Maciel

Can asset allocation limits determine portfolio risk-return profiles in DC pension schemes? / Tomás Frederico Maciel Gutierrez ; advisor: Davi Valladão ; co-advisor: Bernardo Pagnoncelli. - 2019. 45 f. : il. color. ; $30 \mathrm{~cm}$

Dissertação (mestrado)-Pontifícia Universidade Católica do Rio de Janeiro, Departamento de Engenharia Industrial, 2019.

Inclui bibliografia

1. Engenharia Industrial - Teses. 2. Fundos de pensão. 3. Restrições de portfólio. 4. Gestão de riscos. 5. Contribuição definida. 6. Política pública. I. Valladão, Davi Michel. II. Pagnoncelli, Bernardo Kulnig. III. Pontifícia Universidade Católica do Rio de Janeiro. Departamento de Engenharia Industrial. IV. Título. 


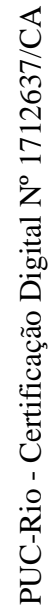

To my family. 


\section{Acknowledgments}

I would like to first thank my advisor Davi Valladão and my co-advisor Bernardo Pagnoncelli for all the support throughout this journey. A mix of guidance, collaboration and friendship that made it not only possible but very rewarding. I would also like to thank prof. Arturo, prof. Street and Thuener for all enriching discussions and for helping me whenever I needed during this past years.

Then I wish to thank all my friends at LAMPS, and all professors that I encountered during the graduate period. Ranging from hard work to amusement, they made it an incredible experience.

On a personal basis, I wish to thank all my friends.

Most importantly, I would like to thank my family, for everything.

Finally, I would also like to thank de CNPq for granting me a scholarship, trusting that I would do a great work.

This study was financed in part by the Coordenação de Aperfeiçoamento de Pessoal de Nível Superior - Brasil (CAPES) - Finance Code 001. 


\section{Abstract}

Gutierrez, Tomás F. M.; Valladão, Davi M. (Advisor); Pagnoncelli, Bernardo K. (Co-Advisor). Can Asset Allocation Limits Determine Portfolio Risk-Return Profiles in DC Pension Schemes?. Rio de Janeiro, 2019. 45p. Dissertação de mestrado - Departamento de Engenharia Industrial, Pontifícia Universidade Católica do Rio de Janeiro.

In defined contribution (DC) pension schemes, the regulator usually imposes asset allocation constraints (minimum and maximum limits by asset class, e.g. equities, bonds, real estate, loans, etc.) in order to create funds with different risk-return profiles. In this work we challenge this approach and show that such funds exhibit erratic risk-return profiles that deviate significantly from the intended design. We propose to replace all minimum and maximum asset allocation constraints by a single risk metric (or measure) that controls risk directly. Thus, funds with different riskreturn profiles can be immediately created by adjusting the risk tolerance parameter accordingly. We demonstrate the effectiveness of this approach with data from the Chilean DC pension system. Specifically, we show that our approach generates funds whose risk-return profiles are consistently ordered according to the intended design and outperform funds created by means of asset allocation limits.

\section{Keywords}

Pension Funds; Portfolio Constraints; Risk Management; Defined Contribution; Public Policy; 


\section{Resumo}

Gutierrez, Tomás F. M.; Valladão, Davi M.; Pagnoncelli, Bernardo K.. Restrições de alocação de portfólio determinam perfis de risco-retorno em modelos de pensão de contribuição definida?. Rio de Janeiro, 2019. 45p. Dissertação de Mestrado - Departamento de Engenharia Industrial, Pontifícia Universidade Católica do Rio de Janeiro.

Em sistemas de pensão de contribuição definida (CD), o agente regulador em geral impõe restrições de alocação (mínimo e máximos por classe de ativo, como renda fixa, ações, empréstimos, etc.) com o objetivo de criar fundos com diferentes perfis de risco-retorno. Neste trabalho, desafiamos essa abordagem e mostramos que tais fundos apresentam perfis de risco-retorno erráticos que desviam significativamente do design desejado. Nós propomos a substituição de todas as restrições de limites máximos e mínimos por uma medida única que controla o risco financeiro diretamente. Dessa forma, fundos com diferentes perfis de risco-retorno podem ser estabelecidos imediatamente ao variarmos tal medida. Nós demonstramos a eficácia dessa abordagem com dados do sistema de pensão chileno. Mais especificamente, mostramos que nossa metodologia resulta em fundos cujos perfis de risco-retorno estão consistentemente ordenados de acordo com o design desejado e exibem performance superior em comparação com os fundos criados com o uso de restrições de limites de alocação.

\section{Palavras-chave}

Fundos de pensão; Restrições de portfólio; Gestão de riscos; Contribuição Definida; Política Pública; 


\section{Table of contents}

1 Introduction $\quad 14$

2 The Chilean Pension System $\quad 17$

$\begin{array}{lll}2.1 & \text { System description } & 17\end{array}$

$\begin{array}{lll}2.2 & \text { Performance of AFP funds } & 18\end{array}$

3 Investment Strategy $\quad 22$

3.1 Scenario generation $\quad 22$

$\begin{array}{ll}3.2 & \text { Formulation and strategy }\end{array}$

$4 \quad$ Numerical Implementation $\quad 27$

$\begin{array}{ll}4.1 \text { Suitability study } & 27\end{array}$

$\begin{array}{ll}\text { 4.2 Building funds with different risk-return profiles } & 29\end{array}$

5 Conclusions 33

$\begin{array}{ll}\text { A Data } & 35\end{array}$

A.1 Indices selection 35

A.2 Descriptive Statistics-Annual Returns 35

B Conditional Value-at-Risk $\quad 36$

$\begin{array}{lll}C & \text { Risk-return Frontier with Different Parameters } & 37\end{array}$

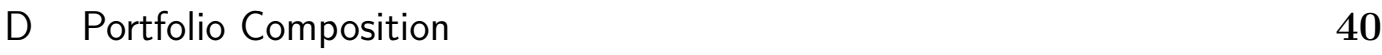

Bibliography $\quad 43$ 


\section{List of figures}

Figure 2.1 Boxplot of shifting 1-year windows returns for each AFP fund.

Figure 2.2 Boxplot of cumulative returns for each fund using shifting 5 -year windows.

Figure 2.3 Boxplot of cumulative returns for each fund using shifting 8-year windows.

Figure 3.1 Shifting $K$-years windows, with $K=4$, during a 6 -year period.

Figure 4.1 Risk-return out-of-sample frontier using CVaR as a risk metric and 9-year cumulative returns of the AFP funds.

Figure 4.2 Cumulative returns for each of the AFP funds, starting in 2006, and using increasing-size time windows.

Figure 4.3 Cumulative returns using the proposed $\gamma$ values, starting in 2006, and using increasing-size time windows.

Figure 4.4 Cumulative returns for each of the synthetic funds, starting in 2006, and using increasing-size time windows.

Figure C.1 Risk-return frontier using CVaR as a risk metric, confidence level of $95 \%$.

Figure C.2 Risk-return frontier using CVaR as a risk metric, confidence level of $99 \%$.

Figure C.3 Risk-return frontier using CVaR as a risk metric, confidence level of $90 \%$, from 2008 to 2013.

Figure C.4 Risk-return frontier using CVaR as a risk metric, $K=5$ years, and confidence level of $90 \%$.

Figure C.5 Risk-return frontier using CVaR as a risk metric, $K=5$ years, and confidence level of $95 \%$.

Figure C.6 Risk-return frontier using CVaR as a risk metric, $K=5$ years, and confidence level of $99 \%$.

Figure D.1 Portfolio composition (left axis) and cumulative out-ofsample return (right axis) obtained by the model using $\gamma=8 \%$ (fund A).

Figure D.2 Portfolio composition (left axis) and cumulative out-ofsample return (right axis) obtained by the model using $\gamma=7 \%$ (fund B).

Figure D.3 Portfolio composition (left axis) and cumulative out-ofsample return (right axis) obtained by the model using $\gamma=6 \%$ (fund C).

Figure D.4 Portfolio composition (left axis) and cumulative out-ofsample return (right axis) obtained by the model using $\gamma=5 \%$ (fund D). 
Figure D.5 Portfolio composition (left axis) and cumulative out-ofsample return (right axis) obtained by the model using $\gamma=4 \%$ (fund E). 


\section{List of tables}

Table 2.1 AFPs' key indicators for annual returns for the period 2006-2014, in percentage terms.

Table 4.1 Values of $\gamma$ associated with each AFP fund's performance. 28

Table A.1 Asset classes permitted and the representative indices selected.

Table A.2 Descriptive statistics (in \%) of the indices used, from 2003 to 2014 . 
Those who cannot remember the past are condemned to repeat it.

George Santayana, The Life of Reason: Introduction and Reason in Common Sense. 


\section{List of Abreviations}

AFP - Administradoras de Fondos de Pensiones

CVaR - Conditional Value at Risk

DC - Defined Contribution

DB - Defined Benefit

GDP - Gross Domestic Product

OECD - Organization for Economic Co-operation and Development

SIEFORE - Sociedad de Inversión Especializada en Fondos para el Retiro

$\mathrm{SP}$ - Superintendencia de Pensiones

VaR - Value at Risk 


\section{Introduction}

Defined contribution (DC) pension schemes have grown in size and importance in recent years. The reason behind this trend is probably the desire by governments and private companies to move away from defined benefit (DB) schemes, since recent demographic tendencies (declining mortality and fertility rates), coupled with low interest rates and anemic growth worldwide, are making it increasingly difficult to manage these liabilities. Moreover, DB schemes often make retirement promises that cannot be fulfilled due to uncertain returns, and the consequences can be disastrous, as shown in [1], [2] and [3].

In the last ten years DC assets have grown at a rate of $7.1 \%$ per year, while DB assets have expanded at a much lower pace (3.4\%)[4]. This same study indicates that DC assets, which in 2005 accounted for $40 \%$ of the total pension funds' assets, today reach $49 \%$. In all, DC funds manage more than US\$ 17 trillion at the end of 2015 .

The growing importance of DC plans has brought with it a new challenge: the need to offer funds with different risk-return profiles to match the different risk tolerance levels of the future retirees [5]. In Chile, for instance, workers can choose from five funds $(A, \ldots, E)$ depending on their risk appetite. In Mexico, the system also offers five alternatives that go from Siefore 0 through Siefore 4, and are more closely linked to the age of the worker. Traditionally, the investment policies of these funds remain anchored on ad hoc rules (minimum and maximum limits by asset class) and do not incorporate any direct assessment of financial risk. The need to bring the investment policies of these funds in line with the risk profile of the workers, as well as their objectives, has been discussed in some detail in [6], although the authors do not propose a specific solution.

A recent report from the Organization for Economic Co-operation and Development [7], which covers both OECD as well as non-OECD countries (104 in total), concludes that in only nine countries pension funds do not have limits by asset classes (e.g. equities, bonds, real estate, loans, etc.). The survey, however, does not separate DC and DB plans. At any rate, a regulation based on limits by asset classes is a well-established and widely adopted practice 
in the pension fund context. Most pension-related publications still focus on limits and not on risk metrics [8], [9], [10]. This is quite intriguing if we consider that [11] establishes a trade-off between risk and return almost 70 years ago. As shown in [12], many pension funds do report risk-related metrics such as Valueat-Risk (VaR) levels or volatility, but always as an a posteriori consideration [13]. These metrics are not an integral part of the investment-decision process.

Back to Markowitz, it is fair to say that the standard deviation of returns is probably not the best metric to gauge risk in the context of a pension plan. In a pension fund what matters is the likelihood of achieving a certain goal (a minimum replacement rate, for instance), and therefore the short-term volatility is almost irrelevant. That said, the basic and deeper idea brought up by Markowitz - that for each risk level there is an optimal portfolio-does not seem to be present in the regulatory developments brought by pension regulators, who still prefers to keep the notion of controlling risk via asset class limits.

The shortcomings of attempting to control the risk profile of an investment fund by means of asset class limits are discussed in detail later in this paper. It suffices to say at this point that the link between asset limits lacks a solid theoretical basis. Furthermore, the empirical evidence shows that such characterization results in funds having erratic time-dependent risk-return profiles that often do not conform to the ordinal relationship expected from them. For instance, by bundling together all types of international equities and limiting their exposure, it is clear that very different risk-return profiles can arise if the equities are from established companies in the United States or Europe, or from emerging markets. The asset class limits model is myopic to those differences, and it should not be surprising to see severe deviations from the intended design when using this approach.

Additionally, in recent years there has been a steady move to switch pension funds from active to passive strategies, due to the higher costs and disappointing performance of active vehicles. For example, [14] shows that in the 15-year period ending on December 2016, 92\% of large-cap, 95\% of midcap, and $93 \%$ of small-cap managers fail to match the performance of their respective benchmarks. Moreover, [15] includes all the US-state pension funds for which there were data available (46 in total) and shows that a simple passive strategy using 14 indices with minimum rebalancing would have outperformed the returns of all but one state in the 2002-2012 period.

One could argue that these ad-hoc rules on limits by asset class are an attempt to steer active management towards good asset allocations. However, it creates a distorted logic, where the regulator imposes limits on the ability to 
actively manage the portfolio to avoid a poor performance from its managers. In other words, it would be an imposition of inefficient rules to control an inefficient management. A transition to a passively managed scheme, by relying on the overall asset classes' performance, would make the system less manager-dependent. As stated in [16], there is no evidence of systematic skilled portfolio managers that outperform persistently. Even more important, a passive management approach usually goes together with lower fees and maintenance costs, which are associated with higher returns [16]. Finally, within each class, the use of indices to invest implicitly attempts to diversify away all non-systematic risk, since most components of each class are part of the portfolio.

In summary, as DC pension plans increase in popularity, there is a pressing need to count on investment techniques that generate good returns along with consistent and distinguishable risk-return profiles. Therefore, the aim of this paper is to propose an alternative investment technique for DC pension funds that offers different risk-return profiles combined with competitive returns. We use data from the Chilean system and develop an active-passive approach (based on a set of indices that represents each a different asset class) that has two distinctive features. First, it controls risk directly using risk measures, that is, it goes away with asset class restrictions. And second, it characterizes risk by limiting expected losses above a threshold, which is more in tune with the medium and long-term goals that are relevant for a future retiree. Such direct control of risk has several advantages: it provides consistent and distinguishable risk-return profiles of the funds, and it requires only one parameter to specify each risk profile. When risk is managed via minimum and maximum limits several parameters are needed, two for each asset class, which by themselves are very difficult to estimate appropriately. At the root of our approach there is an optimization algorithm based on maximization of returns that calls for rebalancing the portfolio weights only once a year, in accordance with a passive approach to long-term objectives. 


\section{2}

\section{The Chilean Pension System}

The Chilean pension system is a DC government-regulated scheme started in 1980 and managed by private asset managers known by their Spanish acronym: AFP. As of the end of 2016, the AFPs, collectively, manage about US\$ 180 billion (equivalent to approximately $70 \%$ of Chilean GDP). There are seven AFPs, and they are restricted by law to have only one line of business: managing the affiliated funds. The Chilean system is a good reference point due to the pioneering role it has played [18]. In fact, more than thirty countries in Latin America, South-East Asia and Eastern Europe have adopted, following the Chilean example, pension arrangements based on a similar architecture. The enrollment in the system is compulsory and workers are required to contribute $10 \%$ of their monthly salaries to their retirement accounts up to a mandatory maximum limit of US\$ 300 per month (as of January 2017). Contributions beyond this limit are optional, and enjoy tax advantages.

\section{1 \\ System description}

In 2002 the system was modified to start offering five different funds, labelled as A, B, C, D and E. The pension regulator states explicitly that the goal of this modification is to have a fund A that, over a long period, should achieve higher returns than fund B, and B better than $\mathrm{C}$, and so on. The regulator, however, does not clarify what a long period is in this context. Additionally, it does not mention explicitly that fund A is supposed to be the riskiest and fund $\mathrm{E}$ the most conservative, even though such implication is clear. The regulator attempts to control the risk level of the funds (which is not defined in any precise way) by limiting the asset class exposures. The admissible assets are: (1) international equities; (2) Chilean equities; (3) international corporate bonds; (4) Chilean corporate bonds; (5) Chilean sovereign bonds; and (6) domestic money market instruments. Investment in alternative assets is not banned but the regulation strongly discourages it and as a result is almost zero across all funds.

The regulator acts under the assumption that equities as well as foreign investments are the riskiest choices, and fixed income and domestic investments 
are the safest. Consequently, it establishes decreasing maximum limits for equities, going from A to E. The maximum limits for fixed income exposures increase in reverse order (going from A to E). For example, fund A must have an equities exposure between $40 \%$ and $80 \%$ measured by market value. In contrast, fund $\mathrm{E}$ has its corresponding limits set between $0 \%$ and $5 \%$. The aggregate fixed income exposure of fund A must be between $20 \%$ and $60 \%$, whereas for fund $\mathrm{E}$ the corresponding limits are $95 \%$ and $100 \%$. Workers who do not make an explicit fund choice are assigned by default to a fund depending on their age, assuming that the risk level decreases from A to E. A more complete description of the system can be found in [19].

Finally, the Chilean system is an ideal benchmark for two additional reasons. First, the pension regulator (known as Superintendencia de Pensiones or SP) publishes regularly monthly returns for each of the funds on its website (www.safp.cl). The data can be downloaded free of charge, and it is routinely audited by third parties. To this day, no irregularities have ever been reported. And second, the returns are reported in inflation-adjusted Chilean pesos (a unit known as UF in Chile). Thus, these figures reflect real (as opposed to nominal) returns. To the best of our knowledge, no other pension system in the world combines availability of audited data, inflation adjusted returns and only minimum-maximum constraints by asset class.

\section{2}

\section{Performance of AFP funds}

In this study we concentrate on the period [January 2006; December 2014], due to data availability. Table 2.1 shows key indicators for each fund in this period, based on industry averages ${ }^{1}$.

\begin{tabular}{lccccc} 
& Fund A & Fund B & Fund C & Fund D & Fund E \\
\hline Mean & 6.62 & 5.81 & 5.43 & 4.96 & 4.73 \\
Median & 10.05 & 7.46 & 4.99 & 5.43 & 5.08 \\
Standard Deviation & 0.22 & 0.16 & 0.11 & 0.07 & 0.03 \\
Sharpe Ratio & 0.31 & 0.35 & 0.49 & 0.73 & 1.68
\end{tabular}

Table 2.1: AFPs' key indicators for annual returns for the period 2006-2014, in percentage terms.

A first inspection of Table 2.1, based on the mean suggests that the performance of the five funds conforms to the order expected by the regulator, that is, $r_{A}>r_{B}>r_{C}>r_{D}>r_{E}$, where $r_{i}$ represents the average annual return of fund $i$. Even though the standard deviation of the returns decreases

\footnotetext{
${ }^{1}$ The regulation induces herd behavior, and since deviations from the industry's mean is heavily punished the returns of all AFPs are essentially identical.
} 
according to the funds intended risk profile, the corresponding Sharpe ratios suggest that the risk-adjusted returns are quite dissimilar.

However, a more precise comparison has to consider different starting periods, and time windows of different sizes. More precisely, we define a shifting $K$-year window as a sequence of data consisting of $12 \times K$ consecutive months. In this way we can analyze what would have happened with a worker that entered a certain fund on any given month and stayed for $K$ years. For instance, with $K=1$ we have a total of 97 periods of 12 consecutive months each, in our dataset. That is, we consider not only periods from January to December (calendar years), but also from February to the following January, March to the following February and so on. Essentially, we analyze sequences of 12 consecutive months. Thus, for a given value of $\mathrm{K}$, we consider all possible sequences of $12 \times K$ months.

Figure 2.1 shows the results for $K=1$. It seems that on average, the system is maintaining the desired order of funds returns, from $\mathrm{A}$ to $\mathrm{E}$, even considering different starting months for the 12-month periods. However, a first disturbing sign appears when we look at the 97 periods individually: only in $46.4 \%$ of the cases the funds returns are in the correct order

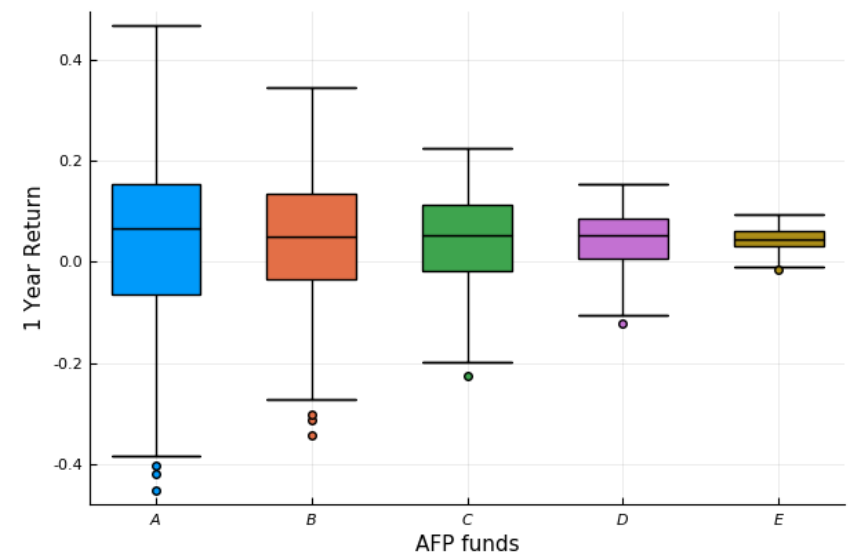

Figure 2.1: Boxplot of shifting 1-year windows returns for each AFP fund.

Since pension funds are mid-to long-term investments, it makes sense to run the same experiment for larger windows. For shifting 5-year windows (periods of 60 consecutive months, Figure 2.2), we notice an even more disturbing pattern: the correct order is violated in $78 \%$ of the windows considered. Moreover, in $53 \%$ of the total cases the order is exactly reversed, that is, $r_{E}>r_{D}>r_{C}>r_{B}>r_{A}$. For shifting 8-year windows (Figure 2.3) the results depart completely from the regulator's intended design: in all cases, the order of cumulative returns is exactly reversed.

We emphasize that in the context of pension funds short-term anomalies, however serious, are not particularly relevant. Windows of five or more years 


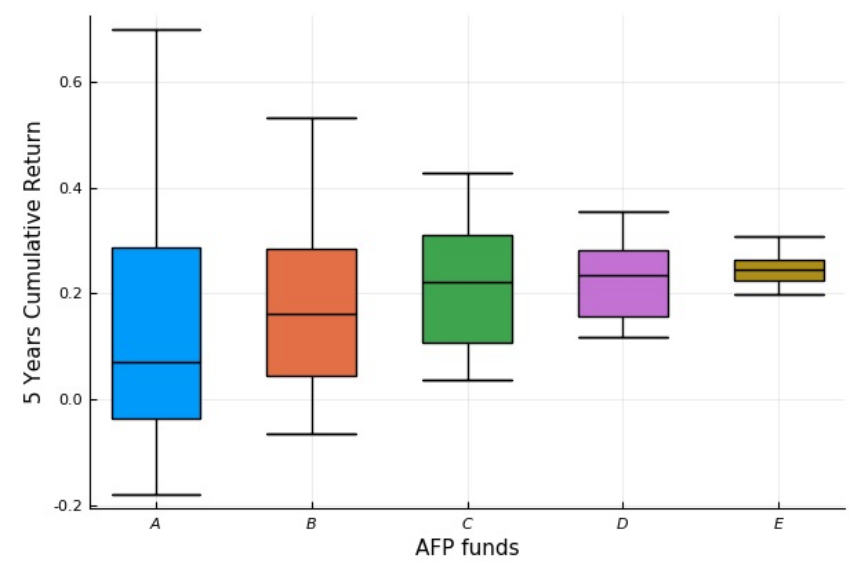

Figure 2.2: Boxplot of cumulative returns for each fund using shifting 5-year windows.

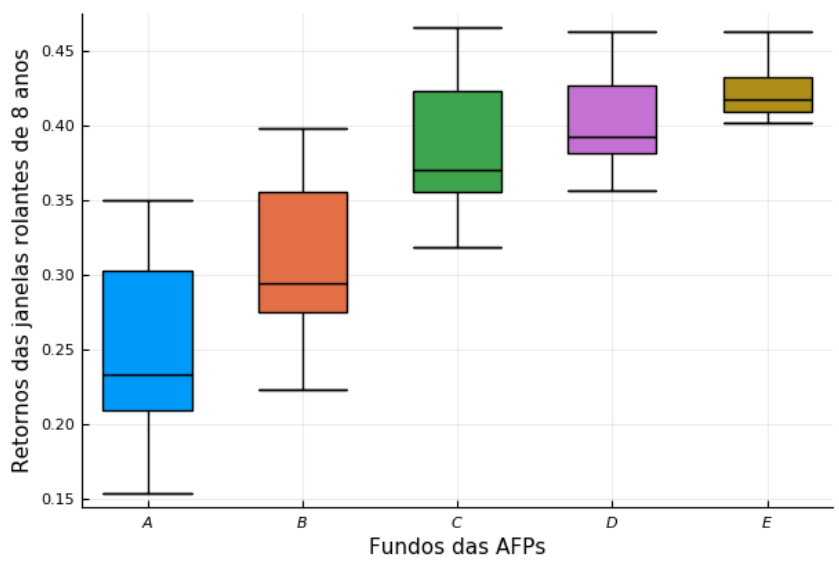

Figure 2.3: Boxplot of cumulative returns for each fund using shifting 8-year windows.

are more relevant: for instance someone who worked 40 years may have stayed 8 years on each fund, as is somewhat typical of life-cycle strategies.

In [5] the author discusses in detail the concept of life-cycle investing, and endorses the view that an individual should start with a high risk tolerance which should decrease gradually over time. In the Chilean context, this implies that a typical worker should join the system by enrolling in fund $\mathrm{A}$, and then move progressively to less risky funds, until reaching fund $\mathrm{E}$ during his final active years ${ }^{2}$. The key assumption behind this strategy, however, is that the riskiest fund (A in our case), over long horizons, should deliver higher returns than fund B, which in turn, should outperform fund C, and so on.

Thus, observing returns in the reverse order intended, over long time periods, should be taken as strong indication that the regulator intentions are not being fulfilled. More to the point: the evidence shows that a person who

${ }^{2}$ Workers who do not choose a fund are assigned first to fund B, then to C, and finally to $\mathrm{D}$, remaining roughly fifteen years on each fund. 
remains for 5 or 8 years in any of the funds, is very likely to experience a return totally at odds with the regulator intentions. For instance, consider a 25-year old worker who wants to take some risks early in her career by choosing fund A and remains in this fund for 8 years, with the hope of obtaining attractive returns. For any 8-year period in our data set this worker would have obtained returns lower than the ones obtained in other funds, an outcome that could compromise her retirement plans in the long run. 


\section{3 \\ Investment Strategy}

The results for the Chilean system presented in Section 2 show that imposing limits by asset classes do not order returns properly. In this section we discuss the sources of this phenomena, and propose an investment strategy that removes those limits completely, and control risk directly.

\section{1}

\section{Scenario generation}

In any portfolio optimization model, we need an estimation of future returns in order to find the optimal asset allocation, balancing risk and return. The usual practice consists of estimating the stochastic process underlying each asset return as well as their correlations, and then generate a number of possible scenarios to be used in the optimization model. However, we face strong obstacles to follow this approach in our problem.

Our approach requires us to estimate annual returns, which can be done in two ways. A first approach would be to use past annual returns and fit some parametric model. The most common approach is to assume returns follow a multivariate normal distribution. Since we are using 6 indices, we would need to estimate 6 expected returns, 6 variances and 15 covariances, totaling 27 parameters. To perform a reliable estimation, we would then need - at the very least -27 past annual returns of each index, which are not available. In [25] the authors show that parameter estimation errors is the main factor that precludes the use of portfolio optimization models in practice, so we decided to avoid such approach.

A second approach would be to use monthly returns as building blocks, and then populate the sample by using some type of bootstrapping technique to create yearly returns out of the monthly data. We tested some popular resampling schemes available in the literature and the results are not encouraging: data are highly correlated, and creating years to be used in the model by pasting data from different months in the past proved to be a poor estimator of future returns.

Faced with these challenges, we decide to pursue a more data-driven, parameter-free approach, as is done, for instance, in [23]. Our proposed 
method relies on moving windows to generate different 12 -month periods. This technique can be seen as a mixture of the block bootstrapping technique, using annualized blocks of historical data, and the historical data approach (assigning equal probabilities to each past scenario), both discussed in [26]. A very similar approach to deal with dynamic data is called time sensitive sliding window, and it is widely used in data mining to obtain frequent itemsets from past observations [27], [28], [29].

The method works as follows: by considering $L$ past years, we have a total of $12 \times L$ months. We can construct a total of $S=(L-1) \times 12+1$ periods of 12 months $(K=1)$ given $L$ calendar years of data by advancing one month at a time (see Figure 3.1). Those $S$ years are going to be the scenarios used in the optimization model, and we assign equal probability to each. A key feature of our method is that it solves the problem of data scarcity without requiring complex parameter estimation, which invariably introduce errors in the formulation.

One could argue that there is an implicit and strong correlation among the possible outcomes, but this is desirable since our aim is to propose a collective strategy for a group of pensioners that enter each of the funds at different months. Moreover, this method has a straightforward interpretation in the pension fund context. A future pensioner can enter the system at any month. An individual who joins in January of a given year would experience a different sequence of 12 months compared to an individual who joins the system in March of the same year. Thus, each sequence of 12 months represents an "actual" past year experienced by some individual(s). In essence, we are considering every possible 12-month sequence from the last $K$ years, and treating it as a potential scenario. Those scenarios will be used as input in our optimization approach that will be presented in the next section.

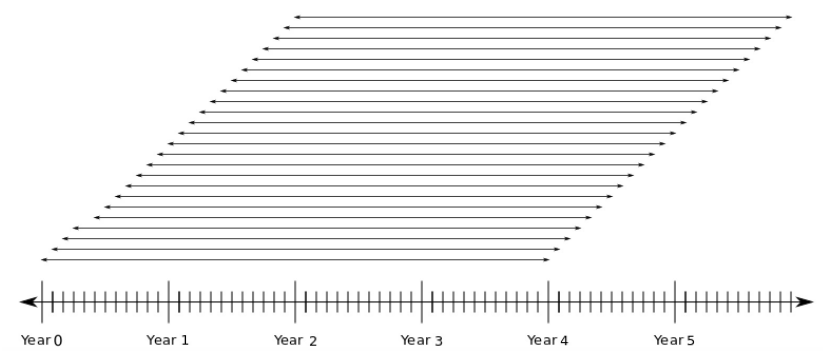

Figure 3.1: Shifting $K$-years windows, with $K=4$, during a 6 -year period. 


\section{2 \\ Formulation and strategy}

Assume we have $N$ asset classes and that for each class we select a representative index (more details can be found in Appendix A). Let $x=$ $\left(x_{1}, \ldots, x_{N}\right)$ be the portfolio weights associated with each index (they must be positive as short selling in general is not permitted, and they must add to one) and $r=\left(r_{1}, \ldots, r_{N}\right)$ be the random vector that represents the returns for each index. Also assume that we have monthly return data regarding the $N$ indices. As we intend to follow an active-passive strategy that rebalances the portfolio once a year, the problem consists of choosing the appropriate portfolio weights at the beginning of the investment period. The choice of a one-year period is somewhat arbitrary: longer periods would hurt the effectiveness of the asset allocation component of our strategy, while shorter periods would call into question the passive component of our approach.

The main aspect of our approach is the removal of all limits on the portfolio positions, except that weights must add one and be positive. Given the portfolio return $r^{\top} x$, we control risk directly using a constraint of the type

$$
\rho\left(r^{\top} x\right) \leq \gamma
$$

where $\gamma$ represents the maximum risk tolerated and $\rho$ is a risk measure. The elimination of lower and upper limits for the portfolio weights simplifies the specification of the problem. Moreover, with no bounds we do not run into the risk of having suboptimal allocations that cannot be improved due to overly strict limits. In [17] the authors present evidence that by varying as little as $1 \%$ the limits of some asset classes, returns can increase up to $4 \%$ annually. Second, the specification of $\gamma$ in (3-1) is simpler than the specification of the many upper and lower asset classes' limits: it represents the desired risk aversion level given some definition of the risk measure $\rho$.

The choice of $\rho$ is an important one, and several possibilities are available. In typical portfolio problems, where the goals are usually short-to-medium term, investors usually concern about the variability of returns, and risk metrics such as the standard deviation are still common choices. In the context of pension funds, which are long-term investments, we believe the risk metric $\rho$ should be related to losses rather than the variability of returns. As we consider an investment period of 12 months, our aim is to avoid possible large "tail" losses that may affect long-term performance.

The risk measure that captures this behavior, and that also has the advantage of being numerically tractable, is the Conditional Value-at-Risk (CVaR), as used in [20] and [30], among others. For continuous random 
variables the CVaR at level $\alpha$ is the expected value of the losses that exceed the $\alpha$-quantile of the distribution. In [21] the authors show that CVaR optimization problems can be converted to linear problems, which can be efficiently solved by off-the-shelf optimization software. We provide more details in Appendix B.

Hence, the optimization problem which is at the core of our investment strategy can be stated as:

$$
\begin{array}{cl}
\underset{x}{\operatorname{maximize}} & \hat{r}^{\top} x \\
\text { subject to } & \mathrm{CVaR}_{\alpha}\left[r^{\top} x\right] \leq \gamma, \\
& e^{\top} x=1, \\
& x \geq 0,
\end{array}
$$

where $\hat{r}$ is the vector of (estimated) average returns for each index, $x$ is the vector of portfolio weights invested in each of the $N$ indices and $e$ is an $N$ dimensional vector of ones.

As mentioned, one of the advantages of using the CVaR is its numerical tractability that allows us to solve our optimization problem as a linear programming problem. This is accomplished by introducing an auxiliary variable, $z$, plus $S$ auxiliary variables $y_{s}$ for each scenario, where $y=\left(y_{1}, \ldots, y_{S}\right)$, noting that $p_{s}$ is the probability of occurrence of each scenario. We denote $x_{i}$ the $i^{\text {th }}$ asset weight in the portfolio, and $r_{i, s}$ is the return of asset $i$ in scenario $s$. By maximizing the expected return of the portfolio, represented by the objective function, we can efficiently solve problem (3-3), which is equivalent to (3-2) given a set of scenarios $r_{i, s}$ :

$$
\begin{array}{cll}
\underset{x, y, z}{\operatorname{maximize}} & \sum_{i=1}^{N} \sum_{s=1}^{S} p_{s} r_{i, s} x_{i} & \\
\text { subject to } & \sum_{i=1}^{N} x_{i}=1, & \\
& z+(1-\alpha)^{-1} \sum_{s=1}^{S} p_{s} y_{s} \leq \gamma, & \\
& y_{s}+\sum_{i=1}^{N} r_{i, s} x_{i}+z \geq 0, & \forall s \in 1, \ldots, S, \\
& y_{s} \geq 0, & \forall s \in 1, \ldots, S, \\
& x_{i} \geq 0, & \forall i \in 1, \ldots, N .
\end{array}
$$

Once we reach an optimal solution, we obtain additional information from the optimization problem. Whenever the risk constraint is active for the optimal portfolio $x^{*}$, the optimal value $z^{*}$ gives the portfolio's Value-at-Risk $(V a R)$, while the values of $y_{s}^{*}$ give us the portfolio's expected loss beyond the VaR under each scenario as follows:

$$
y_{s}^{*}=\max \left(-r_{s}^{\top} x^{*}-z^{*}, 0\right),
$$

where $r_{s}$ is the vector of returns of each asset under scenario $s$. 
The strategy we propose is a rolling horizon scheme that combines an active and a passive element. The active element is the selection of the appropriate weights for the upcoming year. The passive element is due to the fact that within each asset class the investment is done via an index and no rebalancing takes place during the year. As mentioned, by selecting different values of $\gamma$, we can create several portfolios with well-defined and distinctive risk-return profiles, which is aligned with the objectives of a DC pension system. 


\section{4}

\section{Numerical Implementation}

In our first set of experiments we apply our approach and compare it with the performance of the AFPs. Our findings allows us to propose a new scheme for life-cycle allocation problems without portfolio constraints, with coherent risk-return profiles, and easier to implement and interpret.

\section{1}

\section{Suitability study}

In this study, we choose to cast the optimization problem using, as previously mentioned, the $\mathrm{CVaR}$ as a risk metric and we set $K=3$ (number of look-back years to estimate the return scenarios), which results in $S=25$ scenarios. There is no optimal way of selecting the value of $K$, and our choice is guided by having enough data to estimate average returns (values smaller than three generate too much variability). Moreover, 36 months of data is often described in the literature (e.g. [24]) as being adequate for estimation in portfolio optimization models.

By solving the optimization problem described in (3-3), in combination with the return estimation procedure described in Section 3.1, we conduct our experiments over the 9-year period between 2006 and 2014. More precisely, for a fixed value of $\gamma$, we solve problem (3-2), and once the asset allocation $x$ is determined, we compute the actual annual return for this portfolio based on the true return of the indices during that specific year. This last step is what we call out-of-sample results, which is the actual performance realized by the investment strategy.

The process is repeated using a shifting 1-year horizon until 2014: at that point the cumulative return for the period 2006-2014 is calculated. By repeating this process for several values of $\gamma$-ranging from $0 \%$ (most conservative) to $8 \%$ (maximum in-sample yearly loss allowed) - we generate a suitable out-of-sample cumulative return-risk curve. The CVaR is estimated using a $90 \%$ confidence level, and the results are shown in Figure 4.1 (the same experiment for other parameter values can be found in Appendix C).

The curve can be interpreted as a risk-return frontier: for each risk tolerance level $\gamma$ (CVaR constraint), the value along the vertical axis corresponds to 


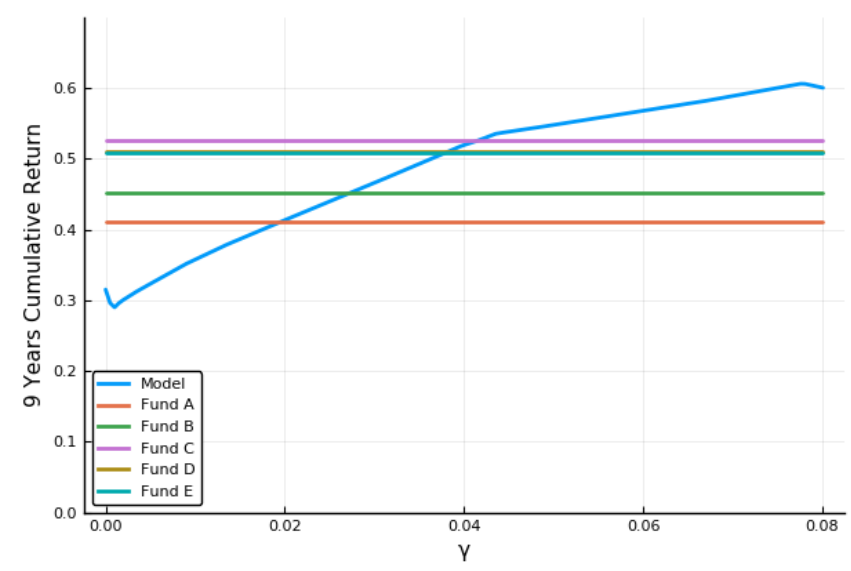

Figure 4.1: Risk-return out-of-sample frontier using CVaR as a risk metric and 9-year cumulative returns of the AFP funds.

the cumulative 9-year return. Second, the curve has the desirable - and by no means guaranteed a priori-property of out-of-sample monotonicity for most of its domain. More to the point, note that for most of the domain increasing values of $\gamma$ go hand-in-hand with increasing cumulative returns, just the way it is desirable. This is a key aspect for using a risk related measure instead of asset constraints. By treating the portfolio as a whole when deciding our allocation, we can balance our exposure to risk from a loss aversion perspective instead of relying on limits by asset classes as risk controls.

Another somewhat surprising result is that the curve intersects all AFP fund's cumulative returns for some parameter $\gamma$. The AFPs are in general active investors that constantly monitor market conditions to find profitable investment opportunities. The implication should be clear: for the 2006-2014 period there existed values of $\gamma$ that could have achieved the same cumulative returns as any of the AFP's funds using our active-passive approach. Table 4.1 shows those values; note that the cumulative returns of the five AFP funds are not ordered in a manner consistent with the desired sequence (monotonically decreasing from fund A to E). Conversely, the fact that the values of $\gamma$ associated with the funds do not decrease monotonically from A to E, provides another evidence that the risk profiles of the AFP funds are at odds with the aim of the regulator.

\begin{tabular}{lcc} 
Fund & Cumulative Return $(\%)$ & $\gamma(\%)$ \\
\hline A & 41.06 & 1.95 \\
B & 45.29 & 2.75 \\
C & 52.62 & 4.15 \\
D & 51.13 & 3.85 \\
E & 50.95 & 3.80
\end{tabular}

Table 4.1: Values of $\gamma$ associated with each AFP fund's performance. 
One could argue that these results are parameter dependent. In Appendix $\mathrm{C}$ we show the same experiment using different time intervals and different CVaR-confidence levels, and the results are essentially the same. That is, our approach generates, in all cases, returns according to the desired risk profile of the funds. However, the returns obtained by the five AFP funds are in disagreement with the desired order. In addition, controlling risk directly, with a single parameter is much more intuitive than attempting to do so via several $\min / \max$ limits at the asset classes level.

In summary, by choosing different values of $\gamma$, we can generate funds with different risk-return profiles. Notice also that the cumulative return of the funds increases monotonically with the value of $\gamma$ for almost all the domain considered. This out-of-sample monotonicity provides us with an ordinal relationship which is the key element to construct life-cycle asset allocation schemes. Hence, our approach is very much in line with the spirit of the riskreturn concept pioneered by Markowitz: the regulator, by selecting different values of $\gamma$, can create a family of funds with well-defined and distinguishable risk-return profiles.

The out-of-sample monotonicity gives us an ordinal relation, which is a key component for life-cycle asset allocation schemes. In the spirit of Markowitz, our scheme generates coherent risk-return profiles, and the only task left for the regulator is to select the values of $\gamma$ to characterize each fund.

\section{2}

\section{Building funds with different risk-return profiles}

Based on our findings, in this section we recommend five values of $\gamma$ that could be used to define the five Chilean funds. Of course, different countries could choose as many values of $\gamma$ as desired, in order to offer a more diverse set of options. Our proposal is as follows: for fund A, $\gamma=8 \%$, fund B, $\gamma=7 \%$, fund $\mathrm{C}, \gamma=6 \%$, fund $\mathrm{D}, \gamma=5 \%$ and fund $\mathrm{E}, \gamma=4 \%$. To be clear, since we are estimating the CVaR with a $90 \%$ confidence, selecting a value of $8 \%$ for $\gamma$ is equivalent of saying that if we consider the worst $10 \%$ loss scenarios, the average of those losses will not exceed $8 \%$.

Figure 4.2 shows the cumulative returns obtained by the five AFP funds using increasing-size time windows starting in 2006. Thus, for example, the first set of bars shows the returns obtained in 2006; the second set, the cumulative returns corresponding to [2006-2007]; and so on. The last set of bars shows the cumulative returns for the entire 9-year period, that is, [2006-2014]. Figure 4.3, which is analogous to Figure 4.2, shows the corresponding returns obtained by the funds designed with our method and the values of $\gamma$ suggested above. The 


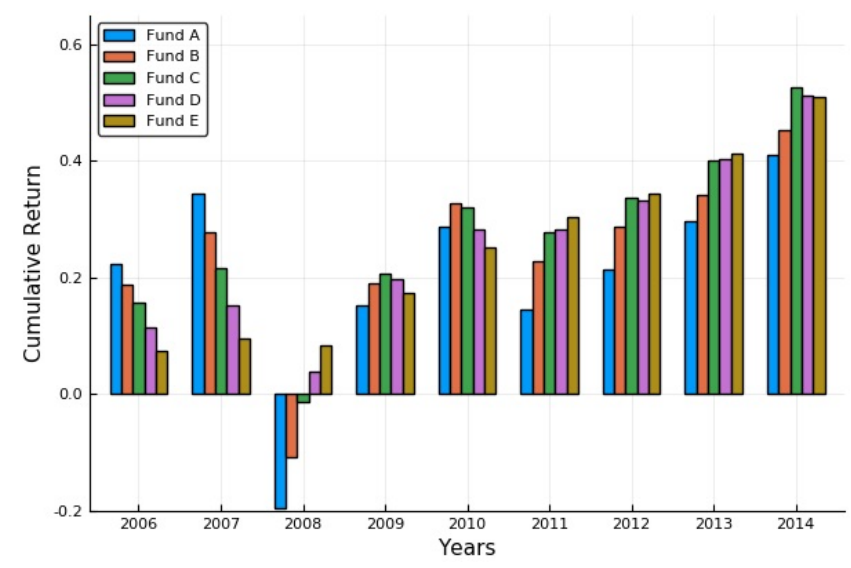

Figure 4.2: Cumulative returns for each of the AFP funds, starting in 2006, and using increasing-size time windows.

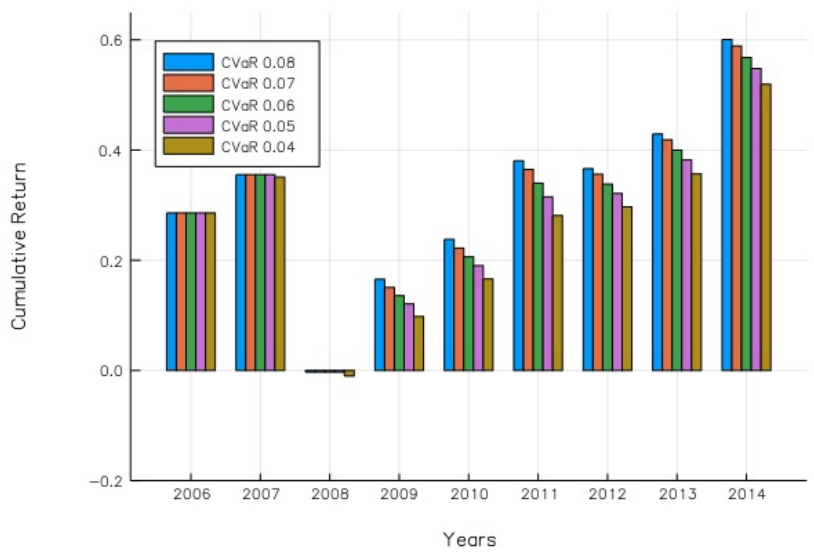

Figure 4.3: Cumulative returns using the proposed $\gamma$ values, starting in 2006, and using increasing-size time windows.

details of portfolio composition are presented in Appendix D.

One could argue that the absence of the desired pattern in terms of riskreturn profiles may be a consequence of the trading strategy of the AFPs, rather than the regulation itself.

In order to explore the merits of this argument, we conduct the following experiment. For each fund (A through E), we cast an optimization problem aimed at maximizing the return of an index-based portfolio subject to the regulatory constraints ( $\min / \max$ limits by asset class). Thus, every January we select the portfolio weights by solving the above-mentioned optimization problem, and then, at the end of December we calculate the actual return of such portfolio. We repeat this process every year, from 2006 until 2014. Figure 4.4, which is analogous to Figure 4.3 shows the corresponding cumulative returns obtained by these synthetic AFP funds.

A visual inspection of Figures 4.2, 4.3 and 4.4 allows us to make the following observations. 


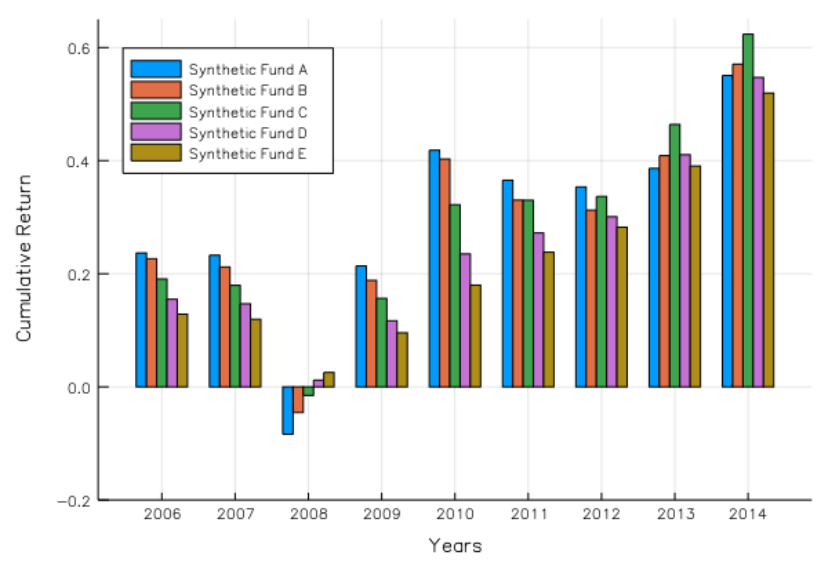

Figure 4.4: Cumulative returns for each of the synthetic funds, starting in 2006, and using increasing-size time windows.

1. Our method, in all cases (see Figure 4.3), results in funds whose returns are commensurate with their desired risk profile (that is, decreasing from A to E). In the case of the AFP funds (see Figure 4.2) this situation occurs only initially; after 2008 the funds exhibit cumulative returns at odds with the intended design. Moreover, the last two sets of bars - the most significant due to the long term nature of the problem - show that the AFP funds returns are ordered in a sequence which is exactly the opposite of what it was intended.

2. When we remove the active portfolio management component and concentrate only of the effects of the min/max regulatory constraints (Figure 4.4), we detect a similar pattern. Namely, although initially the funds are ordered correctly according to their returns, this sequence start to deteriorate in 2008, and never fully recovers. In fact, the disarray is more manifest for the longest time-windows, which is more troubling. In essence, under "normal" market conditions, that is, before the subprime crisis, the deterministic constraints imposed by the regulator, (based on the assumption that equities are riskier than bonds) seem to have achieved the desired goal. However, the crisis has demonstrated the ineffectiveness of this approach. It might be argued, unreasonably of course, that this charge is somewhat unfair since the subprime crisis represents an extreme situation. But the reality is that it is precisely during crises that one needs the regulation to protect the investors, not during "normal" times. The more unsettling issue, nevertheless, is the persistence of the subprime crisis effect: the cumulative returns for the [2004-2016] period - arguably the most relevant from the future retiree viewpoint - are in disarray. 
3. Over this nine-year period, in all five cases, our funds outperform the corresponding AFP funds. In fact, in our approach (compare the rightmost set of bars in Figures 4.2 and 4.3), the lowest performance fund (E, with a $51.95 \%$ 9-year cumulative return) is as good as the best AFP fund (C, with a corresponding $52.62 \%$ corresponding return). The cumulative returns of our strategy and the synthetic one are not too far apart, but only in our model with no regulatory $(\min / \max )$ constraints we obtain ordered returns.

4. Finally, the first two sets of bars in Figure 4.3 are evidence of an interesting phenomenon: in our approach, since risk is controlled directly, it is possible to have the same portfolios (and thus, identical returns) for all five funds, as long as the risk remains within the prescribed bound. If the optimal allocation has very low risk, then all funds should profit from it. The role of risk constraints should be to manage risk exposure, which does not necessarily mean different allocations for each profile under every market condition. In the case of the AFP funds, the portfolios are different by construction, and thus, certain portfolios will necessarily exhibit lower returns compared to the rest. This situation will hurt the investors in those funds since such lower returns will not reflect the risk profile associated with those funds, but rather will be the result of the constraint system imposed by the regulator. 


\section{5}

\section{Conclusions}

In recent years two consistent trends have emerged in the management of pension funds. On one side, DC schemes have grown in both popularity and size. On the other hand, employees are taking a more active role in making decisions regarding how their savings are invested. In this context regulators and sponsors have attempted to offer future retirees a menu of options, i.e. funds with different risk-return profiles so that they can chose the best alternative according to their risk tolerance preferences. So far, the predominant strategy to design such funds has been via min/max constraints at the asset class level. With that as background, two important conclusions can be derived from our study.

First, min/max constraints at the asset class level are a poor proxy to control risk as the link between the overall risk profile of a portfolio and its breakdown by asset class is weak at best. It is the empirical evidence, however, that showcases in a more compelling fashion the shortcomings of the min/max constraints. Our study of the five funds currently offered by the Chilean pension system - all specified in terms of min/max asset class constraints dictated by the regulator - is unsettling. The study not only shows that the funds exhibited risk-return profiles at odds with the regulator intentions, but also that the funds, when ranked according to their respective returns, are ordered in a manner which is exactly the opposite of what was intended (namely, the riskiest fund achieved the lowest return and so on). This trend is more manifested when looking at medium to long term-periods, that is, the periods that are more relevant from a future retiree's perspective.

Second, our investment strategy, which was tested using actual performance data from the Chilean pension system, offers very encouraging results. We start by removing all asset class constraints (except for the fact that portfolio weights must be positive and add to one) and rely on a single risk metricthe Conditional Value-at-Risk in our case - to control risk. We propose an active-passive investment approach in which portfolio weights are chosen once a year, and the exposure to different assets is done via indices. More specifically, our strategy, when applied to the Chilean system, shows that by selecting the risk parameter appropriately we can create five funds that not only outperforms 
the AFP funds in terms of returns, but produces funds with distinguishable risk profiles. In fact, our funds are always ordered correctly in terms of returns (decreasing from A to E).

Additionally, there is something intuitive and appealing from a practical viewpoint about the fact that one can control the risk by manipulating only one parameter as opposed to many, which is the case if one relies on $\mathrm{min} / \mathrm{max}$ constraints. By varying the value of the risk parameter one can use our approach to create an efficient frontier that can help the regulator design a diverse set of funds with different risk-return profiles. Finally, it is important to notice that our test data includes the subprime crisis (2007-2008) - allegedly, one of the most stressful market conditions ever experienced-which adds relevance to the results obtained.

Future work include extending the ideas developed here to a multistage setting, taking into account the whole life of the pensioner. We plan to integrate those ideas with recent advances in regularization techniques to obtain more diversified portfolios. 


\section{Data}

\section{A. 1 \\ Indices selection}

In our experiment, we use a representative index for each asset class allowed under the current Chilean regulation. Due to data availability, the period covered in our study goes from January 2003 to December 2014, with the first 3 years used for model calibration.

\begin{tabular}{ll} 
Asset Class & Representative Index \\
\hline Chilean Equities & MSCI Chile Index \\
International Equities & MSCI All Country World Index \\
International Corporate Bonds & Barclays US High Yield Index \\
Chilean Corporate Bonds & DJLaTixx Chile Corporate Index \\
Chilean Sovereign Bonds & DJLaTixx Chile Government \\
Domestic Money Market & LVA Money Market Index
\end{tabular}

Table A.1: Asset classes permitted and the representative indices selected.

\section{A. 2 \\ Descriptive Statistics-Annual Returns}

\begin{tabular}{lcccc} 
& Mean & Median & Std. Dev. & Sharpe Ratio \\
\hline Chilean Equities & 3.07 & 2.93 & 15.42 & 0.19 \\
International Equities & 8.61 & 5.45 & 24.71 & 0.35 \\
International Corporate Bonds & 5.32 & 4.59 & 12.22 & 0.44 \\
Chilean Corporate Bonds & 5.58 & 4.91 & 5.36 & 1.04 \\
Chilean Sovereign Bonds & 4.16 & 3.85 & 2.15 & 1.94 \\
Domestic Money Market & 0.94 & 0.54 & 2.24 & 0.42
\end{tabular}

Table A.2: Descriptive statistics (in \%) of the indices used, from 2003 to 2014. 


\section{B}

\section{Conditional Value-at-Risk}

The popularity of the CVaR has resulted in several different notations throughout the literature. Since we use extensively the CVaR, we include some definitions for the sake of clarity. The Value at Risk $(\mathrm{VaR})$ of a random variable $X$ with $\operatorname{cdf} F(\cdot)$ and with confidence level $\alpha \in[0,1)$ is defined as

$$
\operatorname{VaR}_{\alpha}[X]:=\min \{t \in \mathbb{R} \mid P(-X \leq t) \geq \alpha\} .
$$

The CVaR of a random variable $X$ and confidence level $\alpha \in[0,1]$ is defined as

$$
\operatorname{CVaR}_{\alpha}[X]:=\frac{1}{1-\alpha} \int_{\alpha}^{1} \operatorname{VaR}_{\gamma}[X] d \gamma .
$$

A key result in [] is the proof that the CVaR can be expressed as the optimal value of the following optimization problem:

$$
\mathrm{CVaR}_{\alpha}[X]=\min _{z \in \mathbb{R}}\left\{z+\frac{1}{1-\alpha} \mathbb{E}(-X-z)_{+}\right\},
$$

where $(a)_{+}:=\max (a, 0)$. Moreover, they show that $\operatorname{VaR}_{\alpha}[X]$ is an optimal solution of the optimization problem described in (B-3). 


\section{C \\ Risk-return Frontier with Different Parameters}

In order to show that the results are not explicitly parameter dependent, we show the different versions of the frontier presented in Figure 4.1. Figures C.1 and C.2 display the frontier using the same time-windows employed to generate the graph shown in Figure 4.1, but with different confidence levels ( $95 \%$ and $99 \%$ respectively). Also, Figure 12 shows the frontier calculated with a 90\% confidence but using instead a different time-frame: [2008-2013] instead of [2006-2014]. As one can see, the behavior remains the same: our approach results in funds ordered correctly in terms of their cumulative returns, while the AFP funds show exactly the opposite pattern.

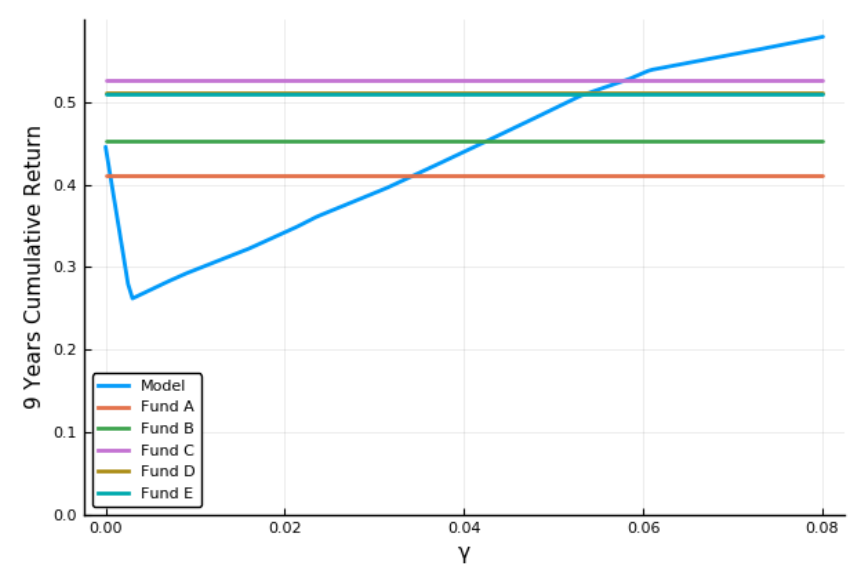

Figure C.1: Risk-return frontier using CVaR as a risk metric, confidence level of $95 \%$.

Another variation that we explored concerns the parameter $K=3$ that we used. Below, we show the out-of-sample frontier using now $K=5$ years. That is, in the scenario generation method, we use now the past 5 years instead of 3 , and perform the whole experiment again. We vary the significance level (again, 90\% in Figure C.4, 95\% in Figure C.5 and 99\% in Figure C.6) and compute the out-of-sample results for the full period of analysis. Once again, we observe the desired out-of-sample monotonicity in reference to the funds returns along with well-defined risk-return profiles. 


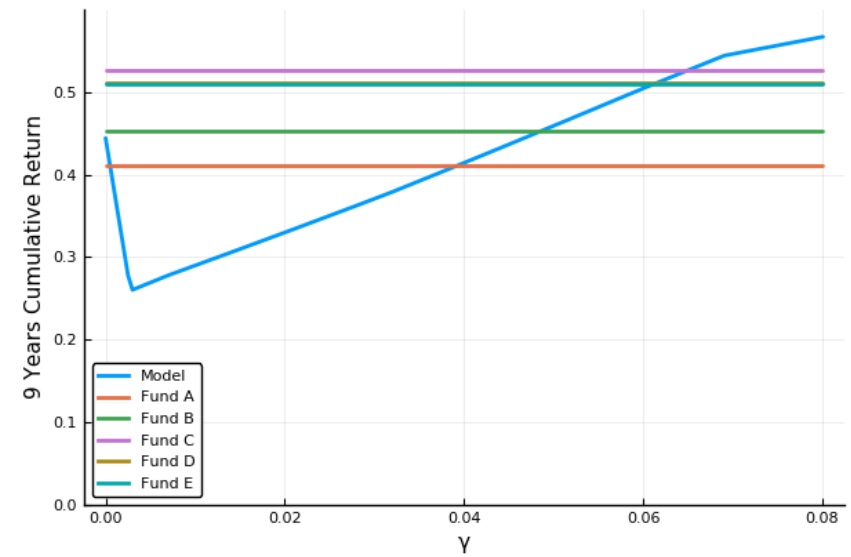

Figure C.2: Risk-return frontier using CVaR as a risk metric, confidence level of $99 \%$.

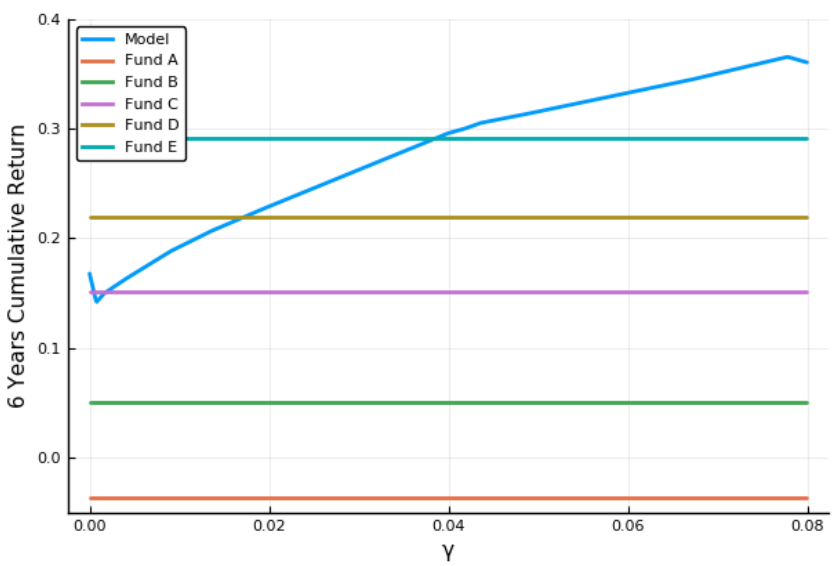

Figure C.3: Risk-return frontier using CVaR as a risk metric, confidence level of $90 \%$, from 2008 to 2013.

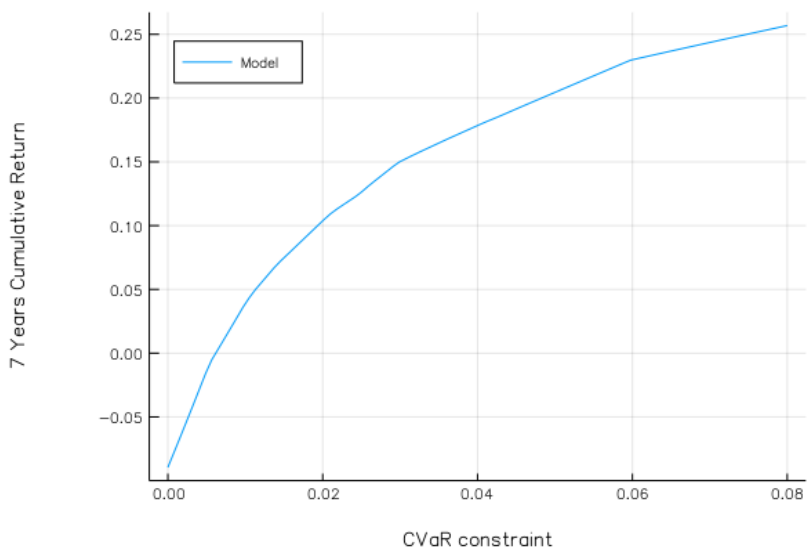

Figure C.4: Risk-return frontier using CVaR as a risk metric, $K=5$ years, and confidence level of $90 \%$. 


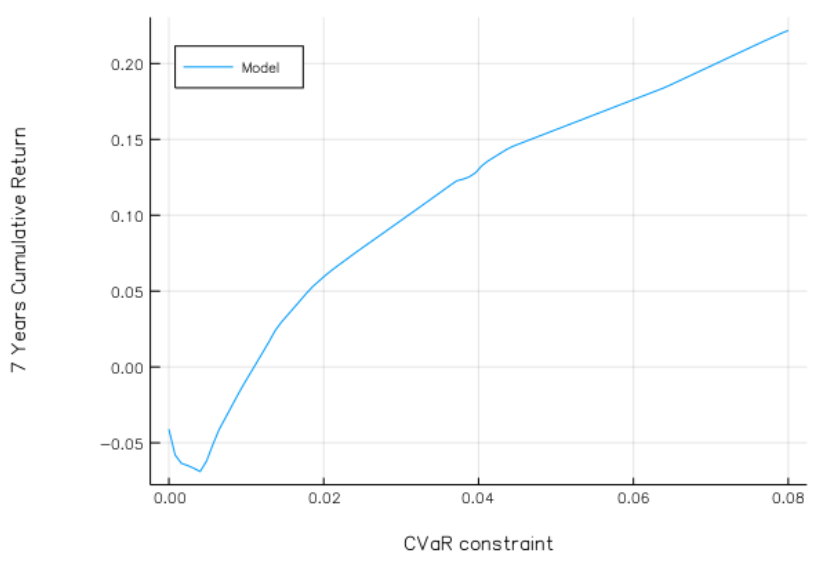

Figure C.5: Risk-return frontier using CVaR as a risk metric, $K=5$ years, and confidence level of $95 \%$.

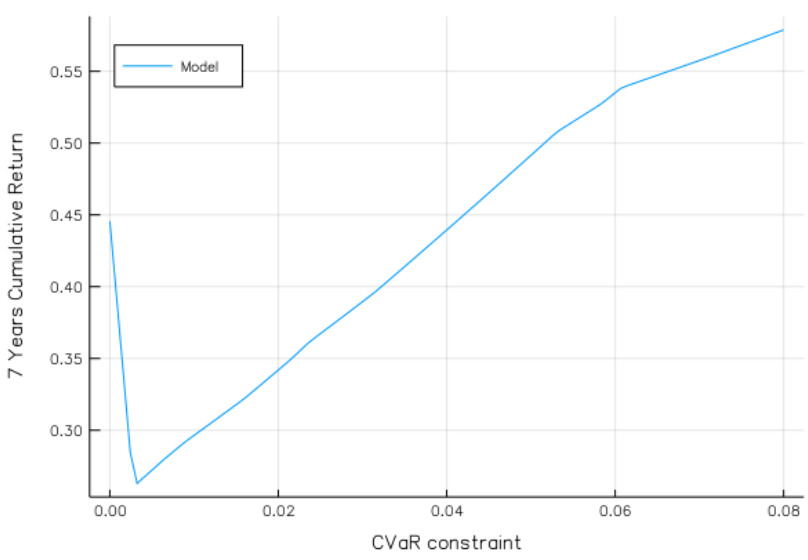

Figure C.6: Risk-return frontier using CVaR as a risk metric, $K=5$ years, and confidence level of $99 \%$. 


\section{D}

\section{Portfolio Composition}

In Figures D.1 through D.5 we show the portfolio composition (weights) for each one of the funds we propose, as well as their cumulative returns, using our approach and the corresponding values of $\gamma$, as indicated in section 4.2. We highlight again the fact that in some years some funds hold identical portfolios (same weights). This means that, for the values of $\gamma$ selected, the risk constraint is not active, which allows all funds to enjoy the maximum returns, without compromising their risk exposures.

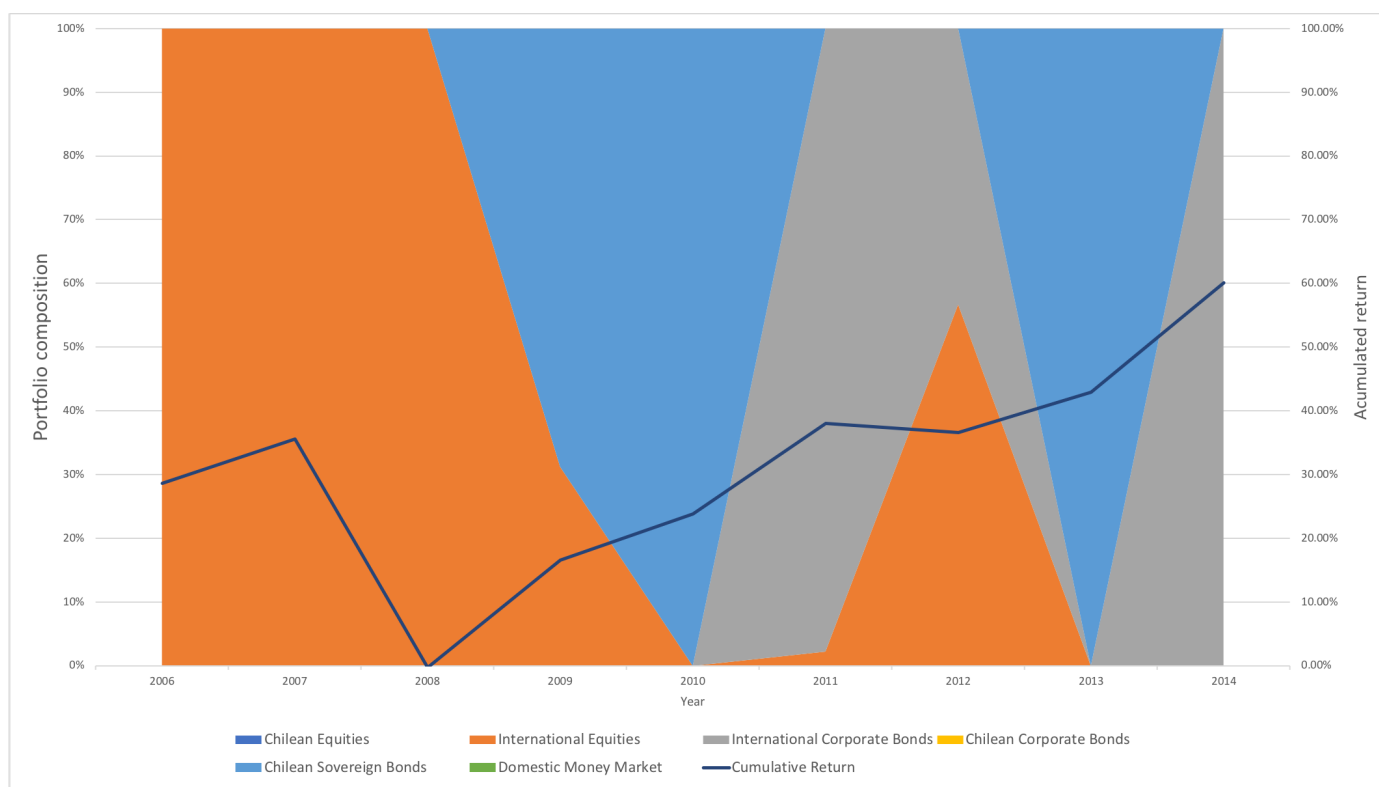

Figure D.1: Portfolio composition (left axis) and cumulative out-of-sample return (right axis) obtained by the model using $\gamma=8 \%$ (fund $\mathrm{A}$ ). 


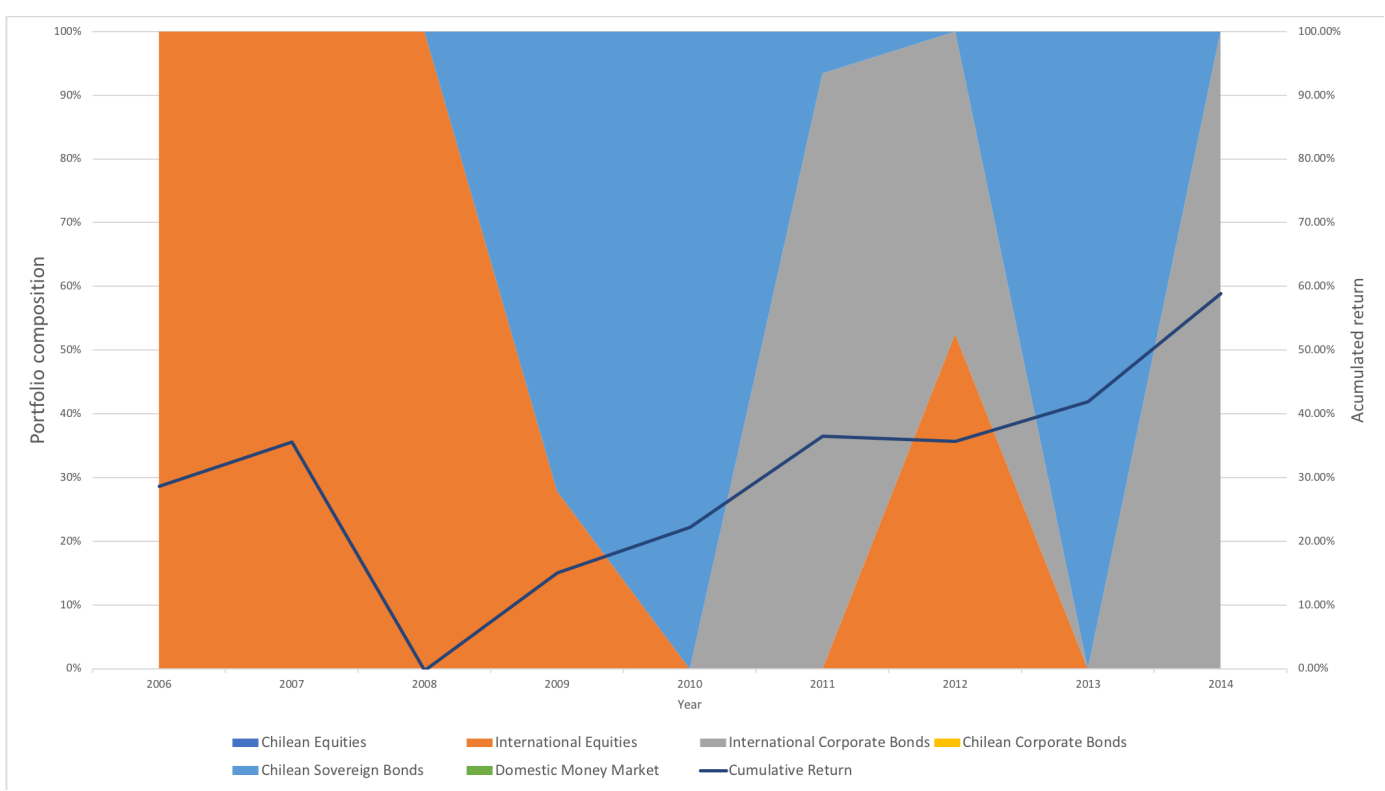

Figure D.2: Portfolio composition (left axis) and cumulative out-of-sample return (right axis) obtained by the model using $\gamma=7 \%$ (fund $\mathrm{B}$ ).

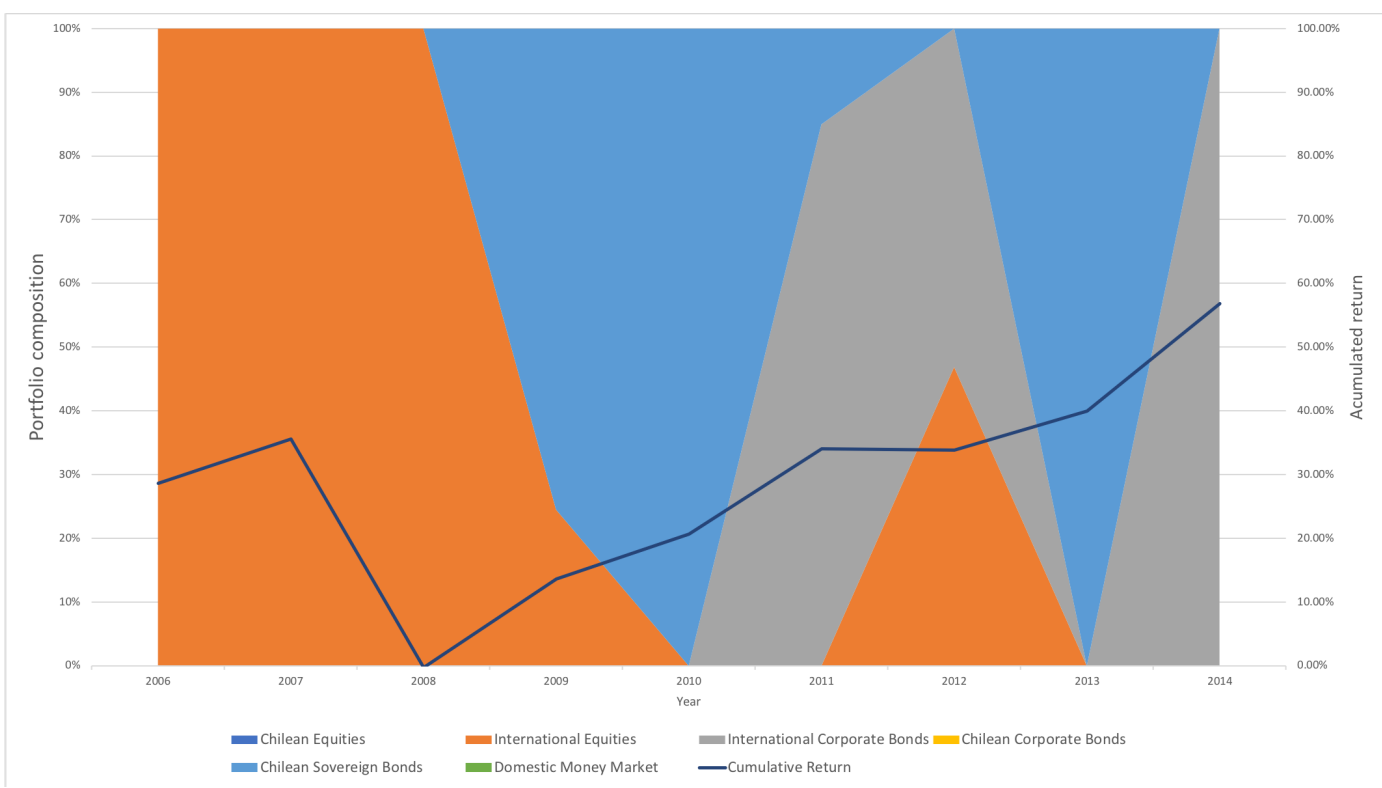

Figure D.3: Portfolio composition (left axis) and cumulative out-of-sample return (right axis) obtained by the model using $\gamma=6 \%$ (fund $\mathrm{C}$ ). 


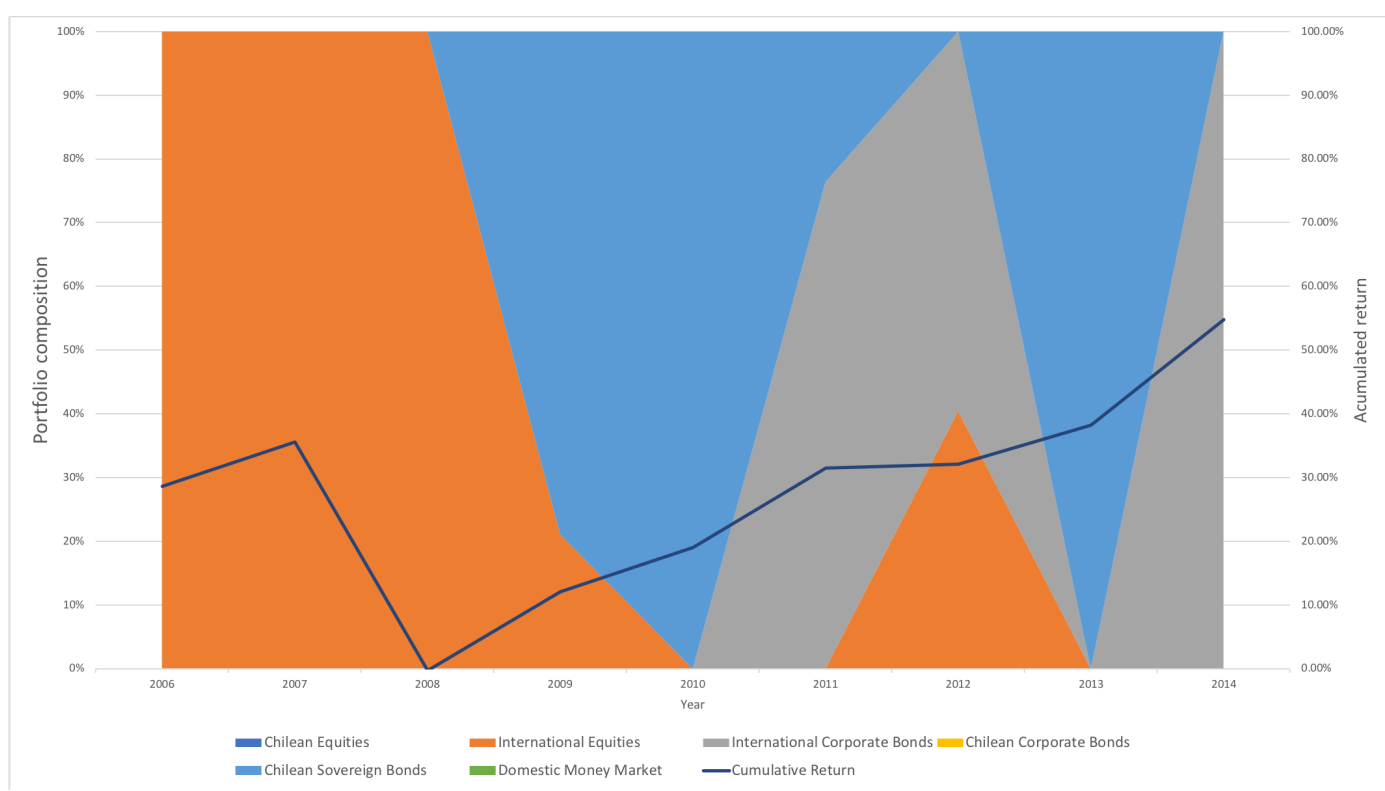

Figure D.4: Portfolio composition (left axis) and cumulative out-of-sample return (right axis) obtained by the model using $\gamma=5 \%$ (fund D).

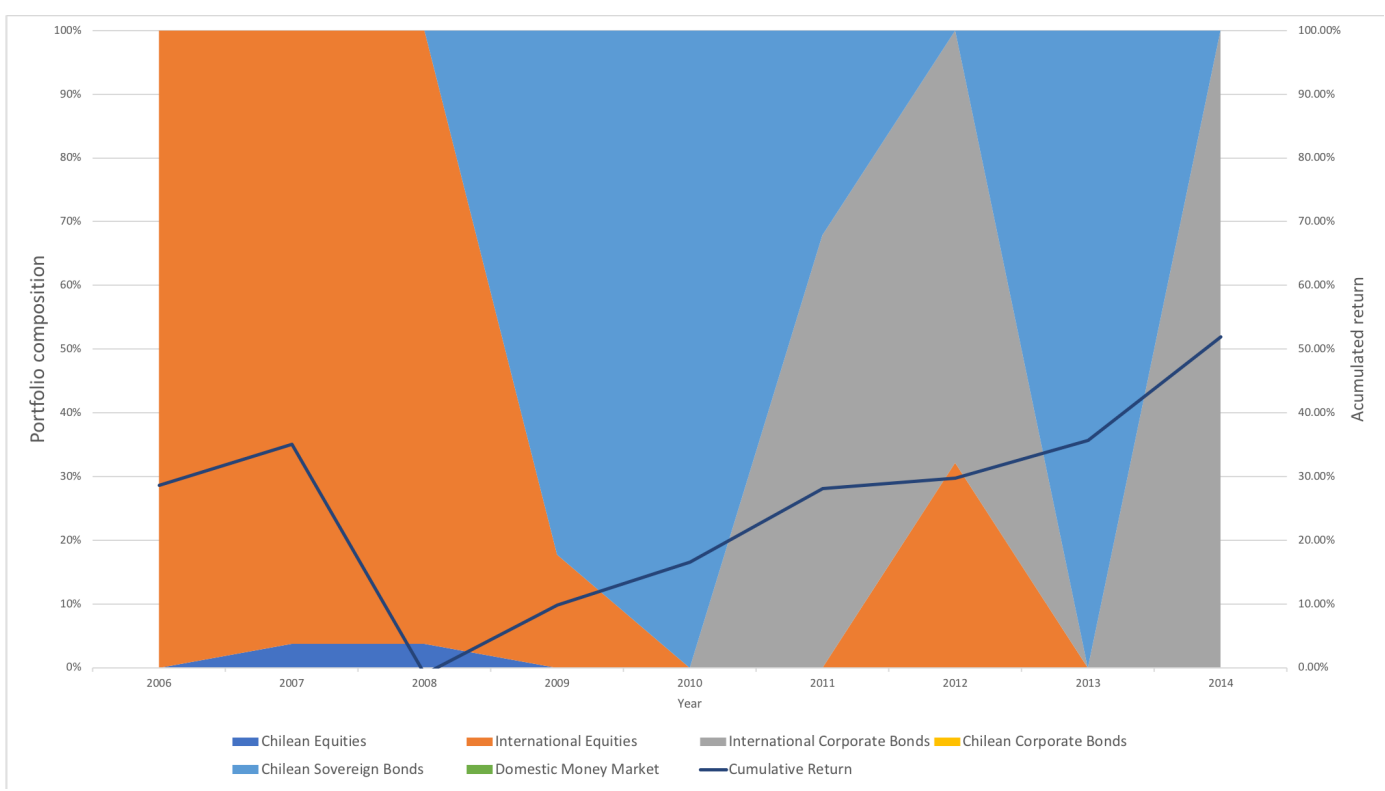

Figure D.5: Portfolio composition (left axis) and cumulative out-of-sample return (right axis) obtained by the model using $\gamma=4 \%$ (fund $\mathrm{E}$ ). 


\section{Bibliography}

[] ROCKAFELLAR, R. T.; URYASEV, S.. Optimization of conditional value-at-risk. Journal of Risk, 2:21-42, 2000.

[1] CLARK, G. L.; MONK, A. H.. The "crisis" in defined benefit corporate pension liabilities part i: Scope of the problem. Pensions: An International Journal, 12(1):43-54, 2006.

[2] CLARK, G. L.; MONK, A. H.. The "crisis" in defined benefit corporate pension liabilities part ii: Current solutions and future prospects. Pensions: An International Journal, 12(2):68-81, 2007.

[3] MALANGA, S.. The pension fund that ate California. City Journal, 2013. Accessed on $10 / 02 / 2017$.

[4] WATSON, W. T.. Global pension assets study. online, 2016.

[5] VICEIRA, L. M.. Life-cycle funds. Overcoming the saving slump: How to increase the effectiveness of financial education and saving programs, $p$. 140-177, 2009.

[6] GARCIA, M.; RODRIGUEZ-MONTEMAYOR, E.. Pension goals and institutional arrangements: Reforms DC 2.0 for Latin America. 2017.

[7] OECD. Annual survey of investment regulations of pension funds, 2015.

[8] GREIFER, N.. A Guide for Establishing a Pension Investment Policy. Government Finance Officers Association, 2003.

[9] OECD. OECD guidelines on pension fund asset management, recommendation of the council, 2006.

[10] PBGC. Investment policy statement, 2016.

[11] MARKOWITZ, H.. Portfolio selection. The Journal of Finance, 7(1):7791, 1952. 
[12] HALIM, S.; MILLER, T. ; DUPONT, D. C.. How pension funds manage investment risks: A global survey. 2010.

[13] DUARTE, T. B.; AO, D. M. V. ; ÁlVARO VEIGA. Asset liability management for open pension schemes using multistage stochastic programming under solvency-ii-based regulatory constraints. Insurance: Mathematics and Economics, 77:177-188, 2017.

[14] SOE, A.; POIRIER, R.. Spiva ${ }^{\circledR}$ US Scorecard. S\&P Dow Jones Indices, McGraw Hill Financial, Year-End, 2016.

[15] WALDEN, M. L.. Active versus passive investment management of state pension plans: Implications for personal finance. Journal of Financial Counseling and Planning, 26(2):160-171, 2015.

[16] CARHART, M. M.. On persistence in mutual fund performance. The Journal of Finance, 52(1):57-82, 1997.

[17] PAGNONCELLI, B. K.; CIFUENTES, A. ; DENIS, G.. A two-step hybrid investment strategy for pension funds. The North American Journal of Economics and Finance, 42:574-583, 2017.

[18] EDWARDS, S.. The chilean pension reform: A pioneering program. In: PRIVATIZING SOCIAL SECURITY, p. 33-62. University of Chicago Press, 1998.

[19] FERNANDEZ, V.. Profitability of chile's defined-contributionbased pension system during the multifund era. Emerging Markets Finance and Trade, 49(5):4-25, 2013.

[20] VALLADÃO, D.; VEIGA, A. ; STREET, A.. A linear stochastic programming model for optimal leveraged portfolio selection. 02 2017.

[21] ROCKAFELLAR, R. T.; URYASEV, S.. Optimization of conditional value-at-risk. Journal of Risk, 2:21-42, 2000.

[23] FERnANDES, B.; STREET, A.; VALLADÃO, D. ; FERNANDES, C.. An adaptive robust portfolio optimization model with loss constraints based on data-driven polyhedral uncertainty sets. European Journal of Operational Research, 255(3):961 - 970, 2016.

[24] BAYRAKTAR, E.; BILGE, A. H.. Determination the parameters of Markowitz portfolio optimization model. arXiv preprint arXiv:1210.5859, 2012. 
[25] KOLM, P. N.; TÜTÜNCÜ, R. ; FABOZZI, F. J.. 60 years of portfolio optimization: Practical challenges and current trends. European Journal of Operational Research, 234(2):356-371, 2014.

[26] GUASTAROBA, G.; MANSINI, R. ; SPERANZA, M.. On the effectiveness of scenario generation techniques in single-period portfolio optimization. 192:500-511, 012009.

[27] LIN, C.-H.; CHIU, D.-Y.; WU, Y.-H. ; CHEN, A. L.. Mining frequent itemsets from data streams with a time-sensitive sliding window. In: PROCEEDINGS OF THE 2005 SIAM INTERNATIONAL CONFERENCE ON DATA MINING, p. 68-79. SIAM, 2005.

[28] FUMAROLA, F.; CIAMPI, A.; APPICE, A. ; MALERBA, D.. A sliding window algorithm for relational frequent patterns mining from data streams. In: INTERNATIONAL CONFERENCE ON DISCOVERY SCIENCE, p. 385-392. Springer, 2009.

[29] DEYPIR, M.; SADREDDINI, M. H. ; TARAHOMI, M.. An efficient sliding window based algorithm for adaptive frequent itemset mining over data streams. Journal of Information Science and Engineering, 29(5):1001-1020, 2013.

[30] BOGENTOFT, E.; EDWIN ROMEIJN, H. ; URYASEV, S.. Asset/liability management for pension funds using CVaR constraints. The Journal of Risk Finance, 3(1):57-71, 2001. 